Original Article

\title{
PREVALENCE OF REFRACTIVE ERRORS IN ADOLESCENTS IN OUT- PATIENT ATTENDEES OF THE PREVENTIVE OPHTHALMOLOGY CUNIC OF COM MUNITY MEDICINE, S K I M S, KASHMIR, INDIA
}

\author{
Jabeen Rohul' ${ }^{1}$, Aakifa Maqbool' ${ }^{2}$, Syed Arshad Hussain ${ }^{3}$, Hamid Shamila ${ }^{4}$, Fazli Anjum ${ }^{5} \&$ \\ Zahoor Ahamad Hamdani ${ }^{6}$ \\ ${ }^{1,5}$ Associate Professors, ${ }^{2}$ Junior Resident (Preventive Ophthalmology), ${ }^{3} \mathrm{~B}$ Grade / Consultant M edicine Department of \\ M edicine, DHP Multispeciality Hospital, Pulwama, ${ }^{4}$ Senior Resident, Department of Community M edicine, SK I M S, \\ ${ }^{6} \mathrm{~B}$-Grade Surgeon, Health Department, J\&K, Srinagar, J\&K, India \\ Correspondence: \\ Syed Arshad Hussain Andrabi \\ B-Grade/ Consultant (Internal M edicine), Tropical Medicine Unit, D H P, M ultispeciality Hospital, Pulwama, I\&K India, \\ Mobile : +9196974 50431, +91 99069 69733; E-mail : syed.arshadhussain@ yahoo.co.in
}

\begin{abstract}
:
Blindness is one of the most significant social problems in India with uncorrected refractive errors as the second major cause accounting for $19.7 \%$ of blindness and low vision.

All adolescents (12-18 years) attending the eye clinic from Jan 2007- Jan 2009 for any eye ailment were examined and screened for refractive error using Snellen's chart.

Out of total 930 adolescents, 508(54.62\%) of adolescents had refractive errors. Of the total males and females examined $57.43 \%$ and $52.12 \%$ respectively had refractive errors. The mean age of presentation was 14.3 years. M ost of the adolescents presented with myopia $257(50.59 \%)$ followed by astigmatism (35.23\%) and hypermetropia (14.17\%).
\end{abstract}

High prevalence of refractive errors warrants early detection and treatment.

Keywords : Refractive errors, adolescents, hypermetropia, myopia, astigmatism

\section{Introduction:}

An estimated 180 million people world- wide are visibly disabled, of whom nearly 45 million are blind, four out of five of them live in developing countries. One third of the world's blind (about 15 million) are in SEAR (South east Asian region) and $50 \%$ of world's blind children live in this region. Blindness is one of the most significant social problems in India with uncorrected refractive errors as the second major cause accounting for $19.7 \%$ of blindness and low vision. In India Adolescents constitute $23-25 \%$ of the population. Poor vision in childhood affects performance in

\section{Access this article online Quick Response Code}

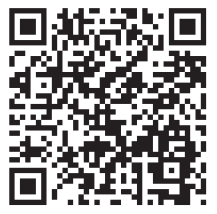
school or at work and has a negative influence on the future life of the child. ${ }^{(1)}$

Three main types are considered as refractive errors: hypermetropia (farsightedness), myopia (nearsightedness) and astigmatism. ${ }^{(2,3)}$ The prevalence of myopia is currently attracting worldwide attention as many recent studies report dramatic increases over the last 20 years. M oreover, planning of a youth's career is very much dependent on the visual acuity, especially in jobs for navy, military, railways and aviation ${ }^{(4)}$.This warrants early detection and treatment of refractive errors to prevent permanent disability. Diagnosis and treatment of these errors is relatively simple and is one of the easiest ways to reduce impaired vision.

Children do not complain of defective vision, and may not even be aware of their problem. They adjust to the poor eyesight by sitting near the blackboard, holding the books closer to their eyes, squeezing the eyes and even avoiding work requiring visual concentration. This warrants early detection and treatment to prevent permanent disability. ${ }^{(4)}$

The present study was carried out in the preventive ophthalmology clinic of the department of community medicine. The study was conducted with the aim of 
assessing the prevalence of refractive errors in adolescents (12-18 years) because any residual hypermetropia of childhood usually gets neutralized by this age and this is the age when children start using their visual system to its full extent so that even minor anomalies are noticed by the patients. It presents the prevalence of refractive errors by age, sex, class, type of error and socio-economic status in Srinagar city.

\section{M aterial and methods:}

All adolescents (12-18 years) attending the eye clinic from Jan 2007-Jan 2009 for any eye ailment were included in the study. All of them were examined by an ophthalmologist present in the clinic. The screening was done from a six meters distance, on Snellen's chart.

Adolescents with visual acuity less than $6 / 9$ were subjected to refraction test at the clinic. Subjective refraction was performed by achieving best corrected visual acuity, while cycloplegic refraction was advised for adolescents when best corrected visual acuity could not be achieved.

Adolescents presenting organic defects in eye such as corneal opacity, opacity of the lens, choroid and retinal disorders were excluded from study.

\section{Results:}

Out of total 930 adolescents examined 493 (53.01\%) were females rest were males (46.98\%). 508(54.62\%) of

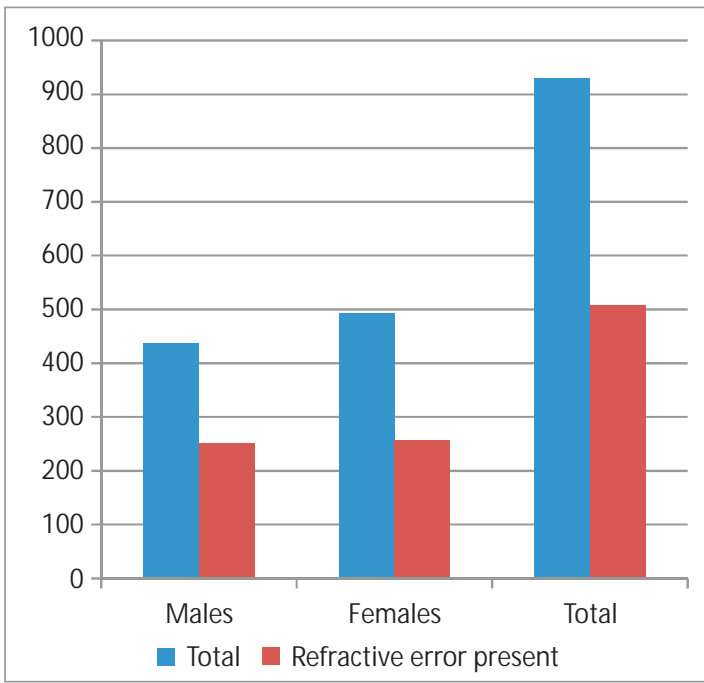

Figure 1 - Gender wise distribution of adolescents with refractive errors adolescents had refractive errors. Of the total males and females examined $57.43 \%$ and $52.12 \%$ respectively had refractive errors Fig -1 . The mean age of presentation was 14.3 years

\section{TABLE 1: Symmetry of refractive errors}

\begin{tabular}{|l|cc|cc|cc|}
\hline & \multicolumn{2}{|c|}{ Isometropia } & \multicolumn{2}{|c|}{ Anisometropia } & \multicolumn{2}{|c|}{ Total } \\
\hline Sex & No & $\%$ & No & $\%$ & No & $\%$ \\
\hline M ale & 201 & $(80.07)$ & 50 & $(19.93)$ & 251 & $(49.41)$ \\
\hline Female & 235 & $(91.60)$ & 22 & $(08.40)$ & 257 & $(50.59)$ \\
\hline Total & 436 & $(86.02)$ & 72 & $(13.98)$ & 508 & \\
\hline
\end{tabular}

Table- I: shows that $436(86.02 \%)$ of adolescents with refractive errors had isometropic error while rest had anisometropia $(13.98 \%)$. M ore females presented with isometropia $(91.60 \%$.) than males(80.07\%)

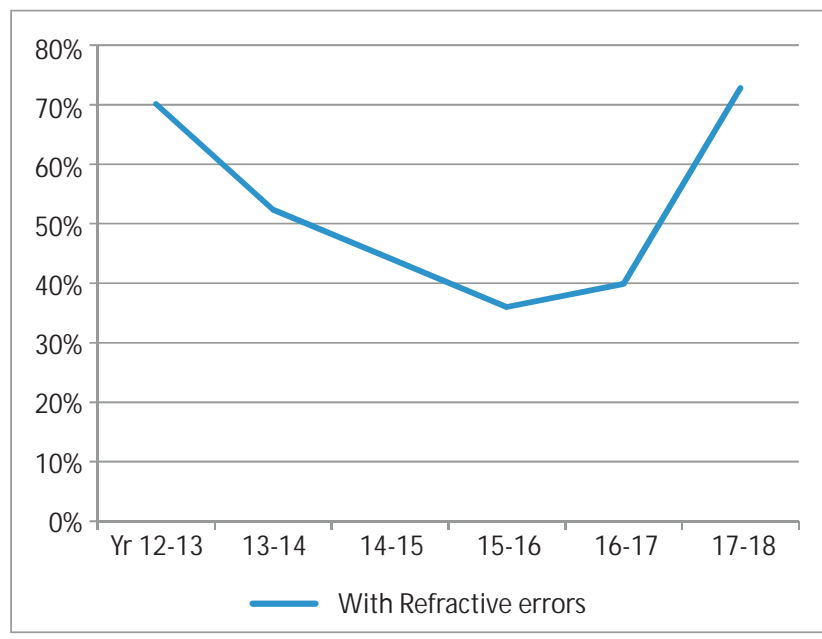

Figure 2 : Line diagram showing age wise distribution of students with refractive errors

158 adolescents presented to the clinic in the age group of $17-18$ years with $73 \%$ of them having refractive errors followed by $12-13$ year age group in whom $70.09 \%$ had refractive errors this was followed by other age groups showing presence of more refractive errors at two extremes of adolescence. Figure-2

Most of the adolescents presented with myopia 257(50.59\%) followed by Astigmatism (35.23\%) and hypermetropia (14.17\%). Both myopia (54.48\%) and Hypermetropia (52.78\%) was found more in females as compared to males. Astigmatism was more prevalent in Males. Fig-3 


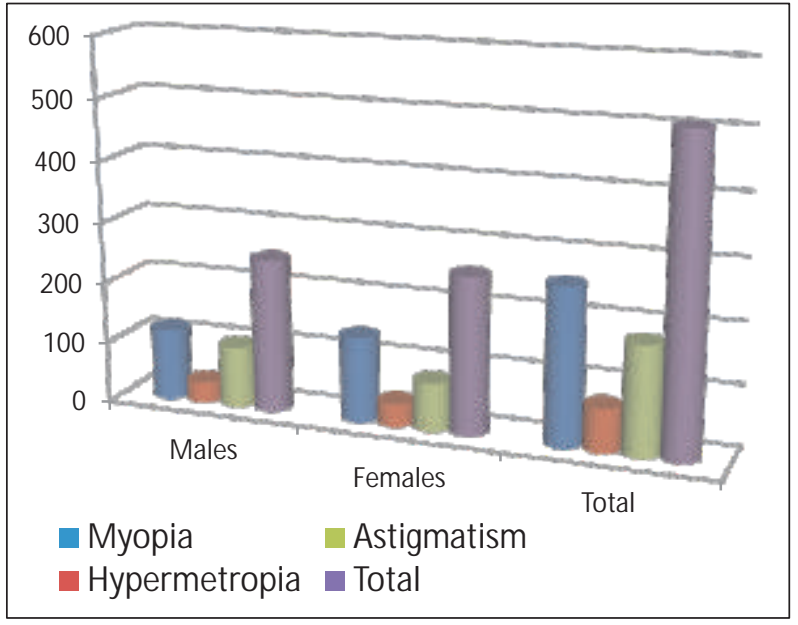

Figure 3-Type of refractive errors

TABLE 2: Family history of adolescents with refractive errors

\begin{tabular}{|l|r|r|c|}
\hline & \multicolumn{2}{|c|}{ Family h/o refractive error } & \\
\hline Type of error & \multicolumn{1}{|c|}{ Total (\%) } & not present & Present \\
\hline M yopia & $100(38.91)$ & $157(61.09)$ & $257(50.59)$ \\
\hline Hypermetropia & $21(29.17)$ & $51(70.83)$ & $72(14.17)$ \\
\hline Astigmatism & $36(20.11)$ & $143(79.89)$ & $179(35.24)$ \\
\hline Total & $157(30.90)$ & $351(69.10)$ & 508 \\
\hline
\end{tabular}

Table- 2 shows that $31 \%$ had a family history of refractive errors. Family history was more in myopics (38.91\%) followed by hypermetropia and Astigmatism $29.16 \%$ and $20.11 \%$ respectively.

We also found that $50.00 \%$ of adolescent's belonged to social class 11 followed by class $111,1 \mathrm{v}$, and v $28.00 \%$, $17.00 \%, 2.00 \%$ respectively.

\section{Discussion :}

In our study the prevalence of refractive errors was quite high at $54.62 \%$. The overall incidence in India has been reported to vary between $21 \%$ and $25 \%$ in patients attending eye outpatient departments. ${ }^{(5)}$ Similar prevalence of refractive errors has been observed among children of 12-17 years in Ahmedabad city. ${ }^{(6)} \mathrm{A}(32 \%)$ prevalence rate of refractive errors has been reported among school children of age 3-18 years from South India. ${ }^{(7)}$ However Matta et al reports a prevalence of $12.5 \%{ }^{(8)}$ Datta et al report a low prevalence of refractive errors (2\%) from Eastern India among primary school children (5-13 years), which could not be explained. . $^{(9)}$ Padhye et al reports cluster-weighted prevalence of uncorrected refractive error in urban and rural children was $5.46 \%(95 \% \mathrm{Cl}$, 5.44$5.48)$ and $2.63 \%(95 \% \mathrm{Cl}, 2.62-2.64)$, respectively. A study reports prevalence of myopia, hypermetropia and astigmatism in urban children as $3.16 \%, 1.06 \%$ and $0.16 \%$, respectively. ${ }^{(10)}$

Internationally, lower prevalence of refractive errors (2.7$5.8 \%$ ) has been reported among children of age $5-15$ years from Africa, Finland, Chile and Nepal as compared to the present study. ${ }^{(1,12,13,14)}$ These differences may be explained by the different diagnostic criteria used by different authors, racial or ethnic variations in the prevalence of refractive errors, different lifestyles or living conditions . High rate of refractive errors in our study population can also be attributed to racial or ethnic variations or different lifestyles or living conditions like watching TV for long hours, or using computers as most of our adolescents are confined indoors due to long standing turmoil in the valley.

Refractive errors found in our study did not differ significantly between males and females. Similarly in a study by Sonam Sethi no significant differences were found between males and females. ${ }^{(6)}$, while in other studies refractive errors were found to be more common in girls than in boys. ${ }^{(7,15)}$ In these studies the differences were related to the possible differences in the rate of growth between girlsand boys.

It was also found that $50.59 \%$ were myopics followed by hypermetropia and astigmatism. Matta S, Laatkeinin and Sonam Seth also report that myopia was more common followed by Astigmatism and Hypermetropia. In our study 17-18 year age group presented with more refractive errors compared to studies which report higher prevalence in 12 13 year age group. ${ }^{(6,8)}$

$38.91 \%$ of Myopics had a family history of myopia, various studies have also proved some relation with respect to family history particularly in myopia ${ }^{(11)}$

\section{Conclusion :}

Prevalence of refractive errors in our study was found to be very high, thereby warranting early diagnosis and treatment to prevent permanent blindness. 


\section{References:}

1. K Park, Parks Text Book of Preventive and social Medicine. $21^{\text {st }}$ Edition 2011

2. Behraman R, Kligman R, Jenson H .Nelson Text 3 ook of Pediatrics, 16 th edition, Philadelphia: W.B.Saunders Co., 2000; 1898-1899.

3. Seet B, Wong, Gan Dg, Saw SM, Balakrishnan V, Lee LK, Lim AS. Myopia in Singapore: taking a public health approach. Br J Ophthalmol. 2001; 85:521-526.

4. Lin LLK, Shih F, Hsiao CK, Chen CJ. Prevalence of myopia in Taiwanese schoolchildren: 1983 to 2000. Ann Acad Med. 2004; 33:23-33.

5. Goswami A, Ahmed E, Shaha PL, Roy IS. An epidemiological pattern of cases of refractive errors. J Indian Med Assoc 1978; 72:227-8.

6. Sethi S, Kartha GP. Prevalence of refractive errors in school children (12-17 years) of Ahmedabad City. Indian J Community Med 2000; 25:181-3.

7. Kalikivayi V, Naduvilath TJ, Bansal AK, Dandona L. Visual impairment in school children in Southern India. Indian J Ophthalmol 1997; 45:12934.

8. Matt.S, Matta P, Dev A. Refractive errors among adolescents attending ophthalmology OPD. Indian Journal of Community Medicine 2006: vol 31. No 2,114-115.
9. Datta A, Choudhury N, Kundu K. An epidemiological study of ocular condition among school children of Calcutta Corporation. Indian J Ophthalmol 1983; 31:505-10.

10. Padhye AS, Khandekar R, Dharmadhikari S, Dole K, Go 